\title{
Realismo e palavra brutal Harold Pinter no Brasil
}

\section{Maria Helena V. Werneck}

\section{A volta ao lar, \\ de Harold Pinter, \\ enc. Ziembinski, \\ Companhia Torres \\ e Brito Produçōes de Cena, \\ Rio de Janeiro, 1967 \\ (Fernanda Montenegro \\ e Sérgio Brito), \\ Arquivo CEDOC/FUNARTE. \\ Antes de $A$ volta ao lar, \\ o Grupo Decisão, liderado \\ por Antonio Abujamra, \\ estreia, em 1964, o \\ espectáculo 0 inoportuno \\ (The Caretaker), \\ considerado o primeiro \\ grande trabalho do grupo, \\ que, na sua trajectória, privilegia a dramaturgia europeia do pós-gurerra. \\ Fonte: http://www.itau cultural.org.br/aplicet externas/enciclopedia}

_teatro.

2As matérias jornalisticas e criticas referidas neste trabalho foram

consultadas no

CEDOC/FUNARTE,

Rio de Janeiro.

Maria Helena V.

Werneck

é Professora da Escola

de Teatro e do

Programa de Pós-

Graduação em Teatro

da Universidade Federal

do Estado do Rio de

Janeiro (UNIRIO);

Pesquisadora do CNPq;

Membro da Cátedra Pe.

António Vieira de

Estudos Portugueses da

PUC-Rio.

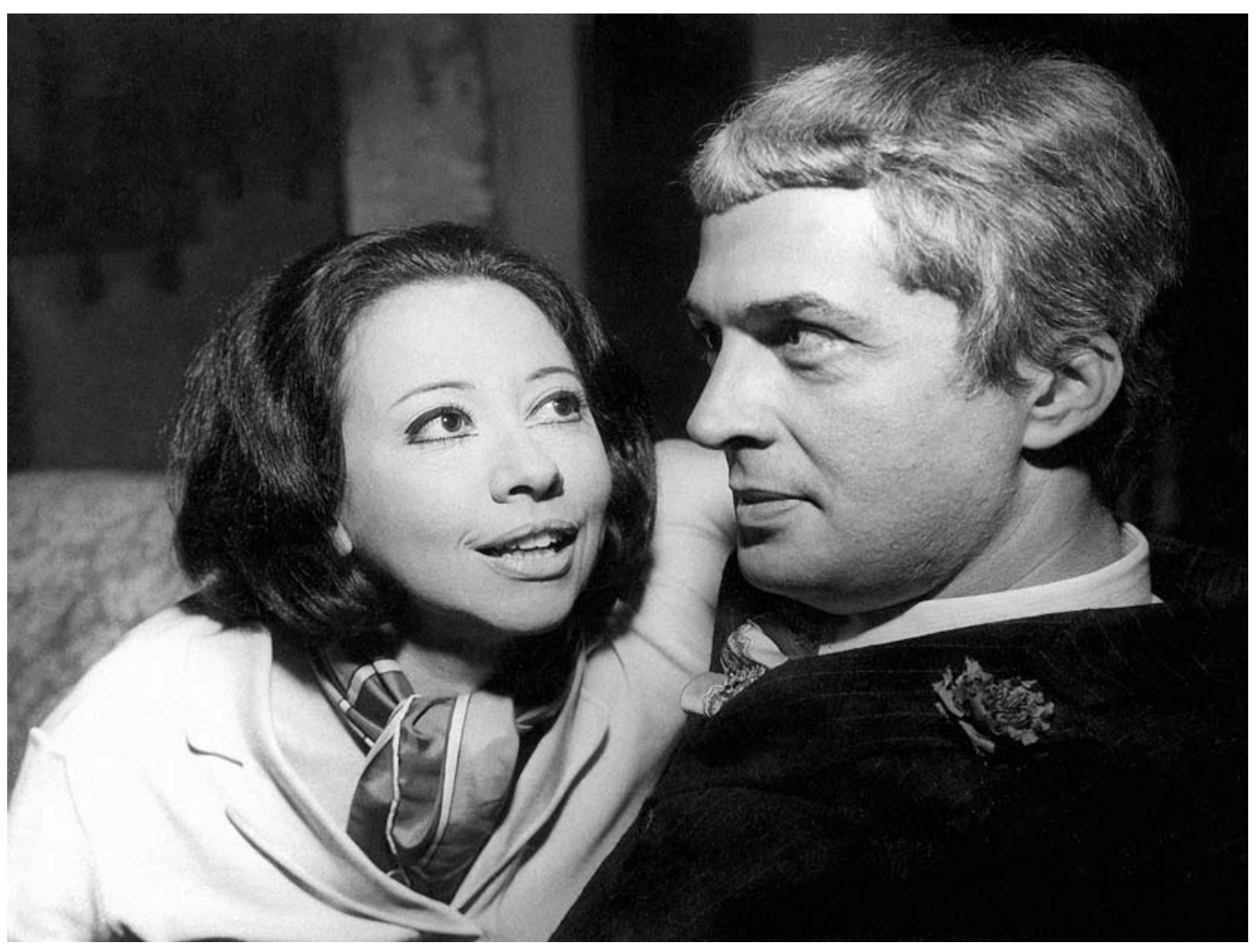

A dramaturgia de Harold Pinter não frequenta os teatros brasileiros com a regularidade com que se faz presente nos palcos portugueses, sendo, no entanto, paixão de alguns actores. 0 veterano Ítalo Rossi, em 2006, dirigiu Duas vezes Pinter (espectáculo com os textos Cinzas a cinzas e Uma espécie de Alaska). 0 actor Selton Mello produziu e actuou em 0 zelador, em 2005. Uma referência a Pinter apareceu, ainda, na biblioteca teatral que o encenador Gerald Thomas invoca, com forte ironia, na dramaturgia de Terra em trânsito, um solo para a actriz Fabiana Gugli, em 2006.

Fugindo da crónica do tempo mais próximo, tomamos o rumo do ano de 1967, quando encontramos uma encenação de $A$ volta ao lar, objecto de nosso interesse neste trabalho ${ }^{1}$. Ao voltar a atenção para o espectáculo, pretendemos realizar no passado recente do teatro brasileiro, "um corte sincrónico para classificar a multiplicidade heterogénea das obras contemporâneas segundo estruturas equivalentes, opostas e hierárquicas e, assim, revelar um amplo sistema de relações" no teatro em determinado momento histórico (Jauss 1994: 46). A proposta é averiguar de que modo a obra de Pinter constituiu, no Brasil, uma espécie de lugar de cruzamento de sistemas histórico-teatrais de referência, que se situam entre a tradição do teatro dos primeiros actores, modernizada pela cena dirigida dos anos 1950, e a eclosão de poéticas cénicas e dramatúrgicas de intensa radicalidade, fenónemo que deslocou para novos patamares a precária tradição realista nos palcos brasileiros.

Entre o material iconográfico do espectáculo, localizamos a foto posada da actriz Fernanda Montenegro, no cenário de $A$ volta ao lar, que, em página dupla, abre a reportagem intitulada "O sucesso de um escândalo", publicada na revista Manchete, periódico semanal de larga circulação na época ${ }^{2}$. Esta primeira imagem permite dimensionar alguns vectores da recepção da peça no Brasil. Fernanda olha séria e firme para a câmara fotográfica, recostada sobre o sofá da sala, elemento central do cenário único da peça. A imagem sintetiza, num lance, o poder da personagem em atrair os homens da 


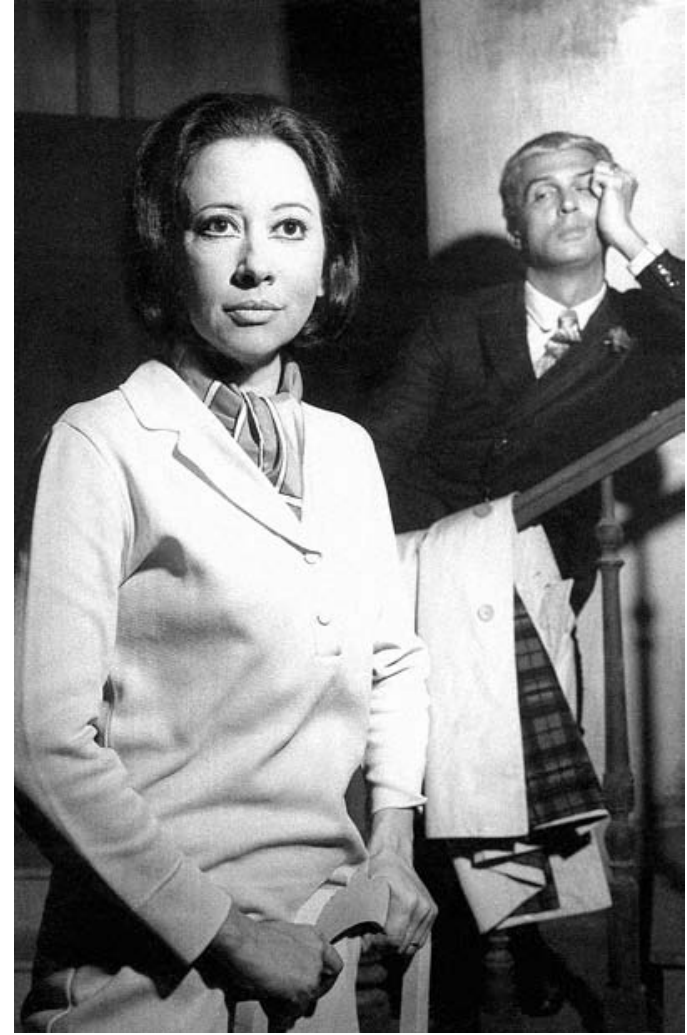

familia que, tanto como a plateia quanto, de imediato, os leitores da revista, passam a ser, progressivamente, capturados seu domínio. Na foto, o que sobressai é um modo corporal, mais sombranceiro e sereno do que provocador, de apresentar-se ao público, que, em princípio, funcionaria como chave antecipadora da recepção da peça.

Observada com mais atenção, a foto constitui, no entanto, falsa pista para o acesso ao espectáculo, porque anuncia apenas parcialmente a lógica das atitudes da personagem Ruth no texto de Pinter. Se continuamos a pensar a recepção teatral com alguns conceitos formulados por Hans Robert Jauss a propósito da recepção literária, a foto da revista "evoca propositadamente um marcado horizonte de expectativas em seus leitores" (o repertório que garante destaque a personagens destinados a primeiros actores das companhias), que, no entanto, a dramaturgia de Pinter e a encenação de Fernando Torres "destroem passo a passo" (1994: 28).

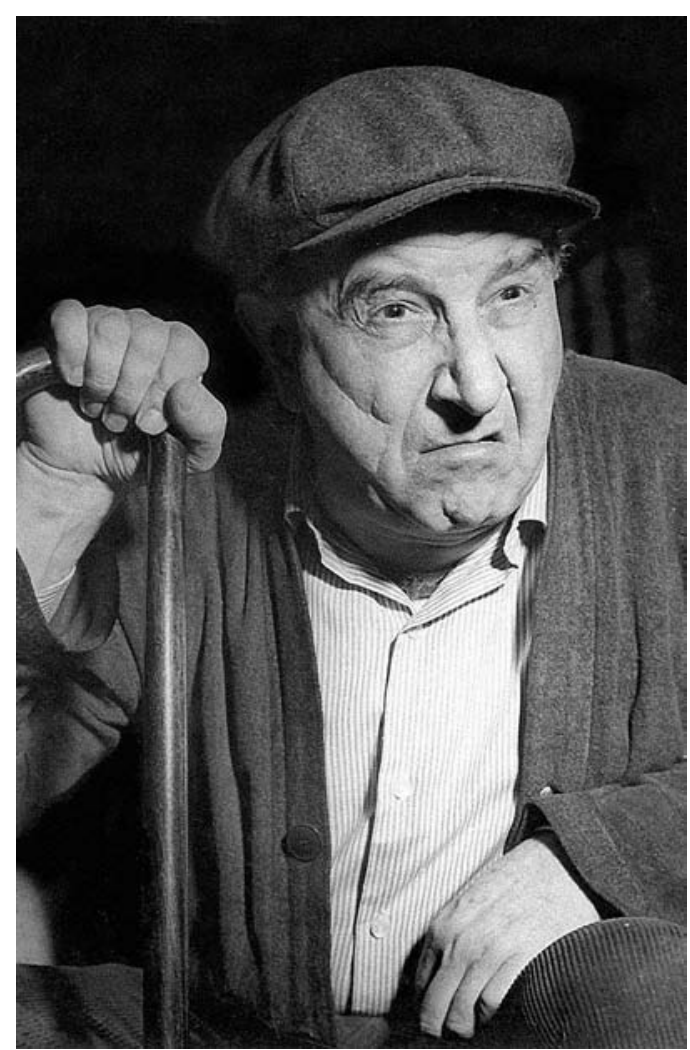

A volta ao lar,

de Harold Pinter,

enc. Ziembinski,

Companhia Torres e Brito Produçōes de Cena, Rio de Janeiro, 1967 < Fernanda Montenegro e Sérgio Brito;

$>$ Ziembinski),

Arquivo CEDOC/FUNARTE
Ao reconstituir-se o horizonte de experiências teatrais do público brasileiro, na década de 1960, é possível detectar a permanência da longa tradição dos agrupamentos artísticos cuja identidade estava centrada na presença ostensiva do primeiro actor-empresário ou da primeira actriz-empresária. A modernidade recém-implantada na década de 1950, com as companhias estáveis de repertório, em que prevalecia, inicialmente, a cena dirigida e o equilibrio da capacidade de actuação, como condição para escalação do elenco, acaba rendendo-se à dinâmica das "fábricas de estrelas" (Brandão 2002: 204). A foto da revista dissemina esta lógica do "divismo tropical" (Brandão 2000: 301), que, na formulação da pesquisadora Tânia Brandão, embora ameaçada pela experiência moderna, continuava entranhada tanto na prática artística quanto na prática recepcional daquele momento do teatro brasileiro.

Longe de ancorar-se na centralidade de um personagem específico, a dramaturgia de Pinter, em A volta ao lar, baseia-se num sistema de rotação de presenças e numa sucessão de solos masculinos, de cuja fonte flui o discurso 
brutal das entranhas ou "o pus", "o vómito", "a bile", para lembrar imagens-chave que caracterizam os actos de fala nesta obra. Percebe-se, assim, no texto de Pinter, como os actos de fala concentram antagonismos, de modo a se efectivar a imagem da cena como o ringue de uma luta de boxe, outra alusão do texto. Num fluxo de falas brutais, a personagem Ruth impõe-se, ao contrário dos homens, pela presença silenciosa, que oscila entre o entrar, o sair, o ficar, o deixar-se cercar, o deixar-se tocar, o deixar-se beijar, impondo, lentamente, o volume do corpo feminino no meio das forças masculinas, que à excepção do marido de Ruth, Teddy, são predominantemente derivadas de bocas que não se calam.

$\mathrm{Na}$ encenação em pauta, tanto os elogios da crítica quanto a ira dos espectadores recairam sobre a actriz Fernanda Montenegro. Os ataques do público durante as duas temporadas, de 1967, no Rio de Janeiro, e de 1968, em São Paulo, explicam-se pela convergência de um esquema prévio de apreensão do público, acostumado a ir ao teatro para ver o grande actor ou a grande actriz, com uma disposição geral conservadora, que se vinha constituindo na sociedade brasileira, desde 1964, antes mesmo do Golpe Militar, resultando em movimentos civis, como a "Marcha Deus pela família e pela liberdade", que teve estratégias de organização a cargo de lideranças e movimentos femininos. A actriz Fernanda Montenegro desabafa, anos depois do espectáculo: "em A volta ao lar. o Movimento da CAMDE (Campanha da Mulher pela Democracia) organizava "protestos diários no meio do espectáculo. Um sofrimento."(Rito 1981: 129).

Percebe-se como a personagem Ruth atrai esta força conservadora e a desconstrói, quando não se justifica em primeira pessoa, nem invoca a simpatia ou a aliança do público. Tampouco o regime do diálogo em Pinter, em que os personagens se compõem como um palimpsesto, dá tempo para que qualquer sentimento moralista se articule durante a encenação. 0 modo de construção do dramaturgo implícito impõe a perda de função de uma fala que, colocando-se ao serviço da percepção consensual da sociedade, estivesse pronta a dar explicações sobre o comportamento dos personagens (Vieites 2006: 61).

Embora, segundo a crítica da época, a actriz tivesse incluido na sua actuação a abertura para "algo que transcende misteriosamente, e de longe, a mera acção que vemos no palco", mostrando " perfeitamente que seu personagem carrega consigo um outro mundo, além daquele que conseguimos conscientizar", como explica o crítico Yan Michalski (1967), é possível reconstituir o modo através do qual a actriz capitalizou um efeito paradoxal para a recepção da peça de Pinter (Prado 1968). 0 contraste entre a elegância impecável do traje e a atitude antiestereótipo da personagem, solicitado pela dramaturgia, provoca curto-circuito na recepção e detona um movimento passadista do público.

A revolta das senhoras e a agressividade com que a peça foi tratada por parcela da opinião pública representam, assim, não só uma demanda conservadora de preservação da imagem feminina na figura da estrela da companhia, mas, principalmente, uma espécie de negativa explícita ao avanço de nova estética teatral, que se forjava como resposta à ditadura militar, que se implantara havia poucos anos. Seria preciso aguardar a próxima década, para que se configurasse, com maior clareza para os espectadores brasileiros, a prática da cena derivada dos trabalhos de grupos teatrais em processos colectivos de criação, que viriam oferecer ao público uma nova estética cénica pautada na des-hierarquização de papéis e funções, de que resulta "a invenção de uma linguagem bastante original" (Fernandes 2000: 14). À fábrica de estrelas passa a contrapor-se, então, outro modo de produção teatral, representado pelo teatro de grupo que, empregando formas colectivas de criação, constrói-se como alternativa a um modelo empresarial - 


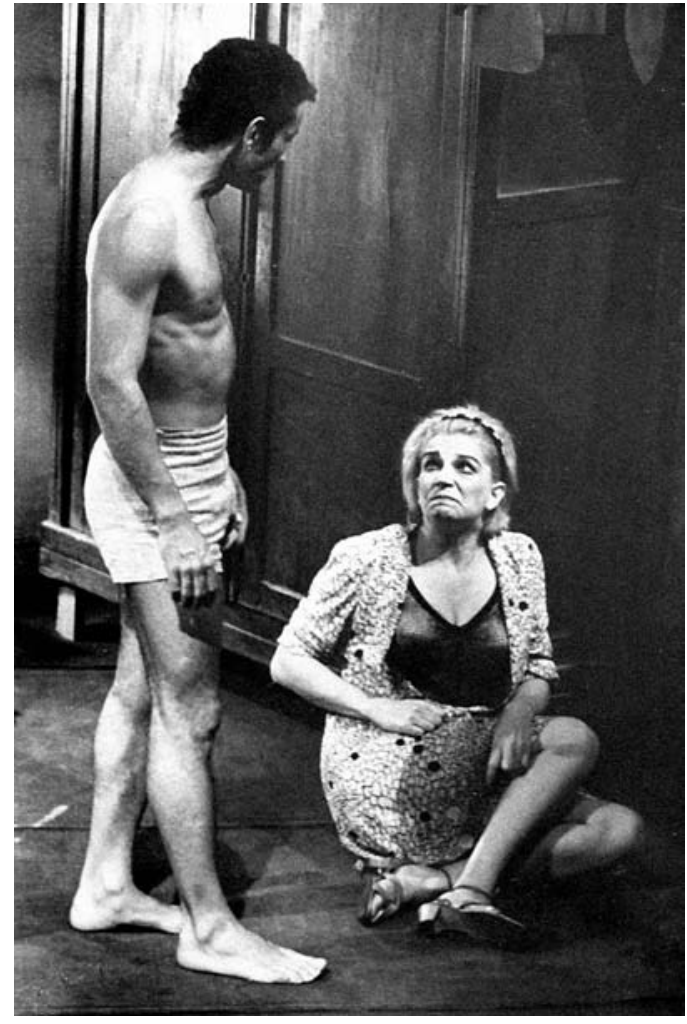

a companhia estável de teatro de repertório - que também se havia tornado economicamente inviável nos anos 60 , no Brasil.

Diferentemente da interpretação de Fernanda Montenegro para a personagem Ruth, a actuação de Ziembisnki para Max teria conduzido a recepção para uma distância mais fortemente marcada, produzindo uma negação da experiência estética familiar. Ziembinski mantém-se no patamar da comunicação intelectual, que exige a percepção da integralidade e da unidade do espectáculo como nova unidade de recepção teatral, modo perseguido pela modernidade (Lima 1980: 23), fazendo avançar "uma mudança de horizonte de expectativas".

Ao cotejar as diferentes apreciações da crítica sobre o actor, percebe-se que em torno da análise do personagem Max constitui-se um núcleo teórico polémico: o novo realismo praticado por Pinter, que não encontra termo de comparação no repertório de referências do espectador, seja ele advindo da dramaturgia estrangeira encenada pelo Teatro Brasileiro de Comédia, seja advindo da dramaturgia brasileira, predominantemente encenada pelo Teatro de Arena, nas décadas de 1950 e 60.

Enquanto o crítico Yan Michalski se enreda em explicar que, em A volta ao lar, há "uma forma puramente realista" que "acaba por ruir como um castelo de cartas", Décio de Almeida Prado, crítico, e também historiador, paulista, dirige os seus leitores para uma escuta mais apurada do texto e para um olhar mais atento à cena (1968). Interessado na modernidade de Pinter, anuncia a prática de um realismo por subtracção, sintetizado no conceito de "adstringência de linguagem cénica". 0 realismo subtraído, proposto pela dramaturgia pinteriana, poderia ser procurado no "fundo de irracionalidade da peça", território de contorno mítico onde se instala confortavelmente o inexplicável. No entanto há um outro limite do realismo a investigar, e este se situa na composição cénica do personagem Max, por Ziembinski.
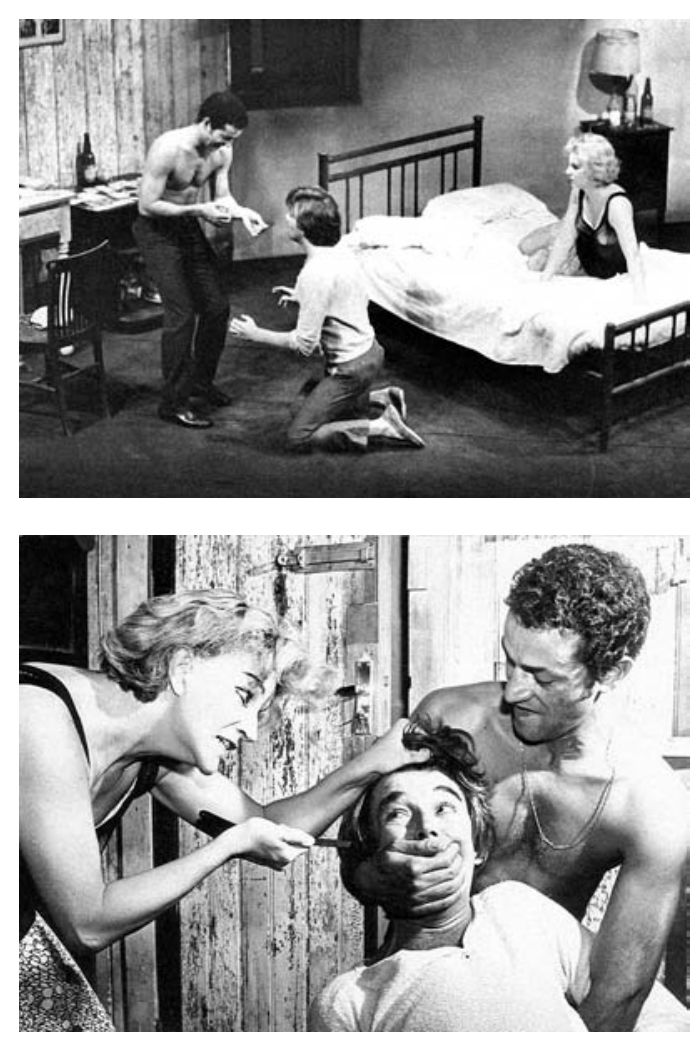

Tanto Prado quanto outro influente crítico, Alberto D'Aversa, percebem que está no papel do pai a fronteira do naturalismo teatral. Tratando-se de um personagem de fronteira, nesta figura haveria "o máximo que Pinter concede ao naturalismo", e, ao mesmo tempo, a sua ultrapassagem, através de "um esquema de falso naturalismo" (1968).

Quando o paradoxo naturalista da dramaturgia de Pinter invoca forças que se medem, sem chegarem, na maior parte das vezes, a se baterem em confronto directo, percebe-se que o que está em pauta é a representação da dinâmica da violência. Neste sentido, a recepção de Pinter no Brasil oferecia à crítica outro caminho interpretativo, menos orientado pela intermitente presença histórica do realismo nos nossos palcos, e mais pela insurgência de uma nova estética, cujas referências residem no campo do teatro agressivo (Rosenfeld 1969: 43).

Observa-se, no entanto, que, em 1967, a discussão sobre a violência representada na cena e sobre a agressão como componente da linguagem teatral acabou confinada ao uso de palavrões. Desta feita, eles não ressoavam nos teatros dedicados às revistas, já em franca decadência, desde a década anterior, ou não eram pronunciados por artistas que faziam do baixo calão sua marca registrada. A sua ocorrência em repertório não identificado com os géneros populares, forneceu munição para a imprensa e para os órgãos da polícia política.

Quatro meses depois da estreia, o espectáculo $A$ volta ao lar foi alvo de um primeiro e violento editorial do jornal o Globo, que a classifica na categoria dos "pornodramas", lamentando que "respeitáveis actores e sobretudo grandes actrizes nacionais" liguem os seus nomes ao teatro obsceno, advertindo certos empresários para que "não transformem o teatro em criação de suínos". No ano seguinte, quando a peça segue para temporada em São Paulo, o emprego de palavras fortes pelos personagens, principalmente Max
Navalha na carne, de Plinio Marcos, Teatro Oficina, 1967 (<Nelson Xavier e Tonia Carrero; $>$ Nelson Xavier, Emiliano Queiroz e Tonia Carrero; $\checkmark$ Nelson Xavier, Emiliano Queiroz e Tonia Carrero), Arquivo CEDOC/FUNARTE. 
e Lenny, logo no primeiro acto, mantém o cartaz no patamar da polémica, tendo como alvo a tradução de Millor Fernandes. 0 tradutor defende-se, em artigo publicado no Correio da Manhã, em 31 de Março de 1968, data do quarto aniversário do Golpe Militar, contra a acusação de ter alterado o texto de Harold Pinter, a fim de tornar a peça mais picante e, portanto, não só comercial, mas também subversiva.

Na véspera da estreia, em São Paulo, a peça é proibida em todo o território nacional e a temporada fica suspensa por quinze dias, durante os quais o director Fernando Torres e o actor Ziembinski negociaram com a representante da Censura, cada palavra mais forte do texto, em episódio que se tornou antológico nas memórias dos tempos da ditadura militar brasileira (Rito 1981: 130). Depois de liberado pela Censura, o espectáculo passou a ser objecto de precauções diárias dos produtores. Temendo ataques à bomba do Comando de Caça aos Comunistas, "a peça só começava depois de todo o teatro ser vistoriado pela polícia" (Ibidem: 131).

Neste ambiente de recrudescimento da repressão, no entanto, sobem à cena espectáculos que, também, se revelam esteticamente agressivos. Yan Michalski, críticotestemunha do teatro durante o regime militar, situa A volta ao lar na primeira fase dos confrontos entre as artes cénicas e a ditadura militar (entre o golpe militar de 31 de Março de 1964 e o dia 13 de Dezembro de 1968, quando é promulgado o Ato Institucional n. 5, o Al-5). Neste periodo, a despeito do embate entre o teatro e 0 regime, dá-se um grande surto de renovação artística. Para Michalski, a necessidade de demonstrar raiva e inconformismo com o ambiente conduz a uma "reformulação muito radical dos próprios conceitos de espectáculo teatral, decorrente da necessidade de contestar os códigos expressivos tradicionalmente aceites como correctos e bem comportados (Michalski 1984: 11).
No mesmo ano da montagem de $A$ volta ao lar, chegam aos palcos duas encenações que se inserem, de modos muito diferentes entre a estética teatral agressiva, apontada por Michalski: Navalha na carne, de Plínio Marcos, e O rei da vela, texto escrito entre 1933 e 1934 por Oswald de Andrade. Percebidas em sua simultaneidade, as três peças indicam uma etapa de experimentação de brutalidade verbal e cénica, que constituia, naquele momento, uma novidade no teatro brasileiro.

A peça Navalha na carne responde à necessidade de colocar o submundo urbano em cena na "crueza de sua matéria bruta" (a luta pela sobrevivência do trio de personagens formado pela prostituta Neusa Suely, o cafetão Wlado e o empregado homossexual da pensão, Veludo). A verve agressiva dos personagens tem fundamento etno-sociológico. As suas falas são determinadas por sua condição de marginalidade. Portanto, há explícita correspondência entre a brutalidade verbal e as figuras representadas em cena. Navalha na carne teve também sua saga de lutas com a censura. 0 espectáculo foi proibido, logo depois da estreia em São Paulo. 0 texto, depois de liberado pela Censura, recebe uma nova montagem no Rio de Janeiro.

A radicalidade da encenação de 0 rei da vela provocou efervescência e adesão de uma parcela significativa do público, embora alguns sectores da crítica tenham sido "reticentes em decorrência do grau de prolixidade, carnavalização, excesso de metáforas, referências pornográficas, fragmentação da linguagem e 'grossura' na representação, que o texto e a encenação propunham" (Freitas 2007: 70). Diferentemente, o crítico Yan Michalski valoriza a irreverência da montagem, vislumbrando nessa experiência o surgimento de um moderno estilo brasileiro de interpretação, "uma fusão de técnicas modernas de anti-ilusionismo com nossas características nacionais de malícia grossa e avacalhada", derivadas de géneros 

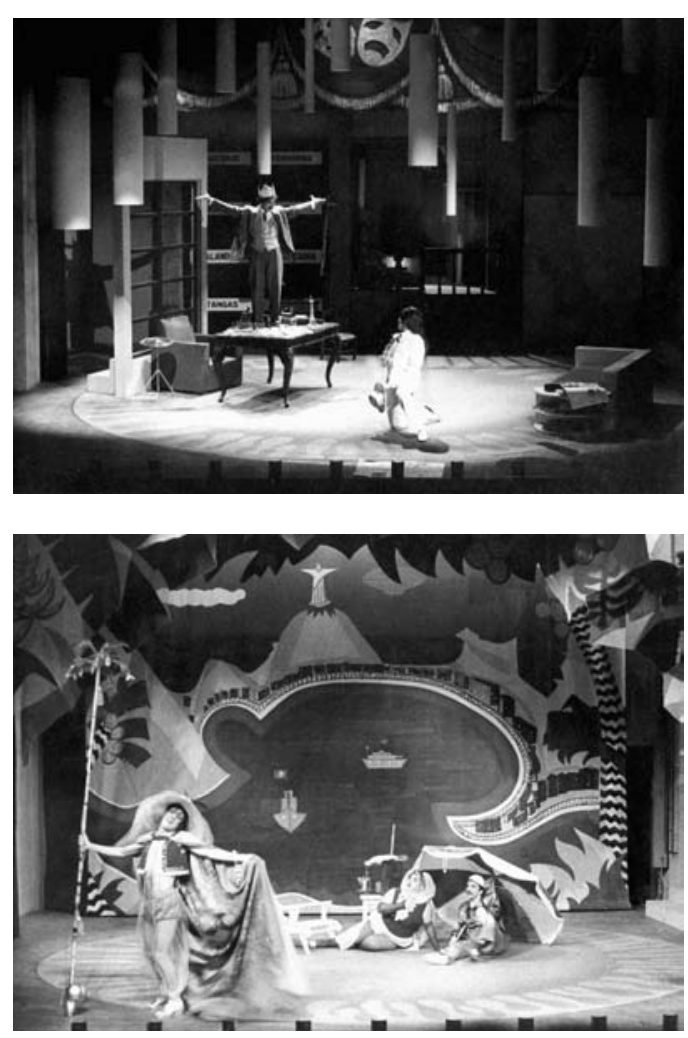

populares como a chanchada, o teatro de revista e o circo (1984: 78), para contar a história de duas gerações de novos industriais que se aliam à aristocracia paulista falida e seguem enriquecendo através da exploração cruel dos mais pobres. 0 espectáculo acabou censurado, assim como todos os textos de Oswald de Andrade, logo depois da implantação do Al-5, em Dezembro de 1968.

Se retomarmos com novos acentos teóricos esta trilogia de espectáculos na qual se insere $A$ volta ao lar, veremos que estamos diante de uma série sincrónica particularmente interessante, a partir da qual poderíamos perceber diferentes poéticas da violência teatral. Nas encenações de textos de autores brasileiros, parte-se de uma homologia figurativista. 0 deboche explicitamente orgiástico de Oswald ganha faces grotescas e figurinos circenses, bonecos pornograficamente monstruosos na encenação do Oficina. Em Plínio Marcos, a representação crua do universo marginal da prostituição pede corpos desnudos, brutos, insidiosos ou desgastados e, ao mesmo tempo, alvos indefesos ao soco, ao estrangulamento, ao corte desfigurante da navalha.

Diferentemente, a dramaturgia de Pinter quase sempre concebe os corpos como suportes a serem preservados da deformidade, que uma ação violenta pode impingirIhes. Não se ferem os corpos explicitamente (há excepções como em The Room). Nas obras do autor dos anos $50 \mathrm{e}$ 1960, eles já chegam em cena gravemente feridos. No entanto, os personagens apresentam-se cobertos por uma camada de maquilhagem, de verniz, ou de lacre que se rompe, paulatinamente, por acção interna que advém ora da oralidade elíptica e colada a acções do quotidiano, ora das falas incontroláveis, chicotes saídos de bocas abertas, que criam zonas de ameaça.

Há, portanto, uma figuração nas personagens do dramaturgo inglês, que emana das forças da fala. A boca diz o contrário do que se expressa na visualidade física

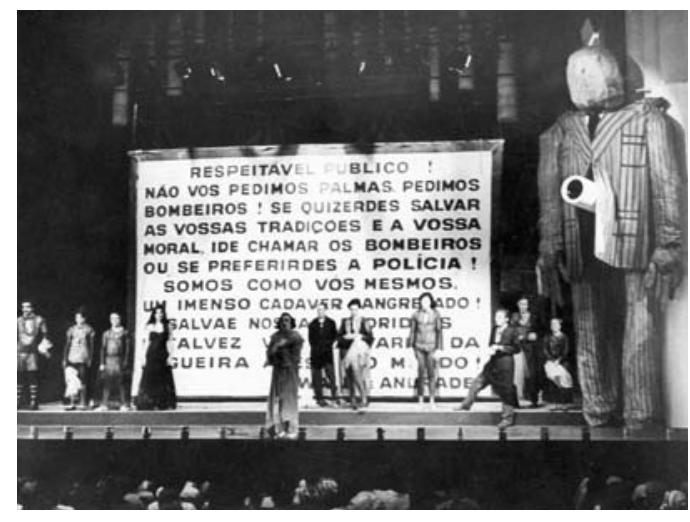

$\hat{<}>$

Oreida vela,

Teatro Oficina,

São Paulo, 1967,

Arquivo CEDOC/FUNARTE

dos personagens. A violência das falas ultrapassa o representado, sobrepõe-se ao desenho do corpo (postura, gestualidade, figurino). São forças invisiveis que estão conformadas, aprisionadas no contorno, no limite da figura corporal ${ }^{3}$ que, portanto, não é expressiva porque homóloga, mas porque contém uma tensão, ou é por onde passa uma tensão, sem que a forma se destrua ou, pelo menos, ganhe nova plasticidade.

No contexto da década de 1960, no Brasil, a incongruente figuratividade do humano em Pinter tornase, assim, um problema de recepção, porque forja uma negatividade intensa, embora baseada na exclusão da redundância, da reiteração ou da conexão directa entre a forma da fala e a forma do corpo. A supressão do carácter duplicador entre o oral e o corporal forja uma equação difícil de encenar no Brasil, naqueles tempos, quando se instala uma linguagem teatral francamente excessiva. A explicitação histérica da brutalidade clama pela presença ilustrativa do corpo no espaço da cena, dizendo em dobro o que a voz diz.

Apostar num "realismo adstringente", ou no uso do silêncio como "potência que as palavras encobrem" (Lima 2000: 3), suprimir a ostensividade da presença do corpo, o seu contorno, o seu volume, a sua cor; impedir a sua possibilidade, mais redundante ou histriónica, de expressar dor e revolta, de alastrar-se e contaminar os que estão em volta, torna-se uma estética inaceitável a um teatro manifestadamente não conformista e de oposição ao regime, no periodo em que a repressão militar começa a aprender a torturar (Gaspari 2002: 357).

Diante de uma prática de recepção acostumada à alta performance individual do actor e face a uma estética cénica de excessiva figuratividade e explícita agressividade, à dramaturgia de Harold Pinter, restou, no Brasil, um certo lugar à sombra, que tempos de intensa e livre experimentação podem, finalmente, iluminar.
${ }^{3}$ Neste parágrafo

estamos pensando com Deleuze ao analisar a pintura de Francis Bacon em cuja obra distingue um problema muito próprio: a aç̧ão de forças invisiveis sobre o corpo (Deleuze 2005: 48). 


\section{Referências bibliográficas}

BRANDÃO, Tania (2002), A máquina de repetir e a fábrica de estrelas: Teatro dos Sete, Rio de Janeiro, Sete Letras.

-- (2001), "Teatro brasileiro do século XX: As oscilações vertiginosas", Revista do Patrimônio Histórico e Artístico Nacional, n. 29, Brasilia, IPHAN.

D'AVERSA, Alberto (1968), "Ziembinski volta ao lar - IV", Diário de São Paulo, 5 de Abril.

DELEUZE, G., (2005), Francis Bacon: Lógica de la sensación, Madrid, Arena Libros. FERNANDES, Silvia (2000), Grupos teatrais: Anos 70, Campinas, Editora da UNICAMP.

FREITAS, Nanci (2007), O homem e o cavalo: Montagem e monumentalidade na estética teatral de Oswald de Andrade, Tese de Doutorado, Rio de Janeiro, Programa de Pós-Graduação em Teatro.

GASPARI, Elio (2002), "O Exército aprende a torturar", A Ditaduro Envergonhada, São Paulo, Cia. das Letras.

JAUSS, Hans Robert (1994), A história da literatura como provocação à teoria literária, trad. Sérgio Tellaroli, S. Paulo, Ática.

LIMA, Mariângela Alves (1980), "Teatro brasileiro: Uma reflexão", DYONISOS, n. ${ }^{\circ} 25$, Set. Teatro Brasileiro de Comédia, MEC: FUNARTE.

-- (2000), "Efeito cómico ironiza impotência da linguagem", O Estado de São Paulo, Caderno 2, 6 de Maio, p. D3.

MICHALSKI, Yan (1967), " Lar, amargo lar", Jornal do Brasil, 9 de Junho.

-- (1984), "O declinio da crítica na imprensa brasileira", Cadernos de teatro, n. 100, Rio de Janeiro, 0 Tablado, SNT, INACEN.

PINTER, Harold (s/d), A volta ao lar, trad. de Millor Fernandes, Rio de Janeiro, Biblioteca da FUNARTE, original datilografado.

PRADO, Décio de Almeida (1968), "A volta ao lar de Pinter no Teatro Maria Della Costa", O Estado de São Paulo, 14 de Abril.

RITO, Lúcia (1981), Fernanda Montenegro: 0 exercício da paixão, Rio de Janeiro, Rocco

ROSENFELD, Anatol (1969), "O teatro agressivo", Texto/Contexto, São Paulo, Perspectiva.

VIEITES, Manuel (2006), "Harold Pinter y lo real: deconstrucción o reconstrución?", ADE Teatro, n. ${ }^{\circ} 11$, julio-septiembre, Madrid, Associación de Directores de Escena de España.

\section{Anexo}

Titulo: A volta ao lar (The Homecoming, 1965). Autor: Harold Pinter. Tradução: Millôr Fernandes. Direcção: Fernando Torres. Interpretação: Sérgio Britto (Lenny), Ziembinski (Max), Delorges Caminha (Sam), Cecil Thiré (Joey), Fernanda Montenegro (Ruth), Paulo Padilha (Teddy). Assitente de direção: Cecil Thiré. Cenário: Túlio Costa. Execução do cenário: Dorlof. Supervisão dos figurinos: Kalma Murtinho. Fernanda Montenegro foi vestida por Celeste Modas e A Cinta Moderna. Cabelo: Bruno do Copacana Pálace. Roupas masculinas: Windsor e Varsano. Figurinos: Sérgio e Padilha: Antonio Dia. Director de cena: Marco António. Electricista: José de Mattos. Maquinista chefe: Antonio de Lourenço. Guardaroupa: Mariléna de Carvalho.

Local e data de estreia: Teatro Gláucio Gil, Copacabana, 8 de Junho de 1967.

Titulo: Navalha na carne (1967). Autor: Plínio Marcos. Direcção: Jairo Arco e Flexa.

Interpretação: Ruthnéia de Moraes, Paulo Villaça e Edgar Gurgel Aranha (substituido depois por Sérgio Mamberti).

Local e data de estreia: Teatro Maria Della Costa, São Paulo, Setembro de 1967.

Título: Navalha na carne (1967). Autor: Plínio Marcos. Direcção: Fauzi Arap. Interpretação: Tônia Carrero, Nélson Xavier e Emiliano Queiroz. Local e data de estreia: Teatro Maison, Rio de Janeiro, Outubro de 1967.

Fonte: http://itaucultural.org.br/aplicexternas/enciclopedia_teatro

Título: O rei da vela (1933-1934). Autor: Oswald de Andrade. Direcção: José Celso Martinez Correia.

Interpretação: Renato Borghi, Itala Nandi, Dirce Migliacio, Etty Fraser, Fernando Peixoto, Otávio Augusto, Chico Martins, Edgar Gurgel Aranha. Cenografia e figurino: Helio Eichbauer. Produção: Teatro oficina.

Local e data de estreia: Teatro Oficina, 29 de Setembro de 1967. 